\title{
Research on Coastline Automatic Extraction Methods Based on Remote Sensing Images
}

\section{Tian Wei}

\author{
Petroleum Technology Information Department, Huabei Oilfield Branch, Renqiu, Hebei, China
}

Liu Wensong

China University of Petroleum (Huadong), Qingdao Shandong, China

\begin{abstract}
In view of the characters of mouth area, such as wide area shallow muddy water and mud deposit coast, morphological automatic algorithm based on wavelet transformation is introduced. The first step of this method is differentiating vegetation from soil effectively by spectrum spatial revolution, with linear transformation it is done in multi spectrum space formed by remote sensing images. Image noise is eliminated with multi scale and direction image noise elimination method which is based on wavelet transformation. Coast line is extracted rapidly, with combination abstracted mud spatial distribution data in shallow sea water, in this step we use image divide automatic seek seed point, rapid increasing algorithm, smooth-edged, edge tracing methods etc. The algorithm we used has the following advantages, such as computing rapidly, high automation, small personal effect, it supplies effective comparison coast line data for the continuously analysis.
\end{abstract}

KEYWORD: morphological approach; coast line; automatic extraction methods; remote sensing

\section{INSTRUCTIONS}

Yellow River has less water and more sand and silt erosion and frequent alternation unique evolutionary characteristics, and the Delta coastline of the Yellow River alluvial silt coast, affecting the entire coastline of the Yellow River Delta combination of factors in the Yellow River sediment and marine power, the occur quickly silting and erosion and a series of evolution. This high frequency of coastal evolution to the ecological environment and coastal engineering facilities Delta brings serious security risks [1]. Especially in recent years drastically reduced the amount of water and sediment of the Yellow River, its shoreline erosion tends to lead to serious.

Changes in the Yellow River Delta coastline have been a complex issue of great concern to many domestic scholars [2]. In the past 20 years (1980 to 2006), many domestic scholars and experts did a lot of research work from different aspects on the coastline temporal evolution of the Yellow River Mouth features, and they have made many research results. Method that in particular the use of satellite remote sensing technology used to study changes in the Yellow River shoreline from a macro point of view has been recognized by many experts and scholars $^{[3]}$. There are many ways to extract the coastline from satellite remote sensing images, including the following method that Screen digitizing, threshold method, band ratio method and classification[4]. These methods have advantages and disadvantages. Such as, the method of screen digitizing is simple, but it has low accuracy, large workload and high requirements for personnel[5]. Threshold method that extracts the coastline has poor accuracy due to sediment and tidal water. Band ratio method is more complex[6]. Visible remote sensing itself, weather conditions and atmospheric conditions of image restricted classification[7].

Considering the advantages and disadvantages of the various methods and available information above case, this paper presents an automatic recognition algorithm based on mathematical morphology wavelet transform. The algorithm is a fast clustering algorithm that combines wavelet transform and morphology graphics [8]. It can achieve the extraction of water sideline rapidly and automatically [9]. Firstly, the wavelet algorithm processes the image and removes false edge. Secondly, the results are combined with spectral features make operation fast clustering. It will not only improve the detection accuracy but also improving the operation speed and improves the shortcomings of past water sideline extraction algorithm [10]. 


\section{COASTLINE EXTRACTION ALGORITHM}

\subsection{Typical characteristics of the coastal zone pixels}

In order to fully understand the spectral characteristics of the Yellow River estuary delta coastline pixels, chose six typical spectral samples of the Landsat ETM + image on 6 September 2004. These samples represent the different types of the
Yellow River mouth delta coastline and table 1 shows the specific type.

Sampling points chosen from the land to the sea line and samples near 80 (40 on each side) pixels, Then we analyze the various types of shoreline of spectral characteristics. Figures 1-6 show Gray- scale variation diagram.

Table 1 Typical data sheet of coastline

\begin{tabular}{|c|c|c|c|c|c|c|c|c|c|}
\hline NO. & Type & Longitude & Latitude & TM1 & TM2 & TM3 & TM4 & TM5 & TM7 \\
\hline 1 & Old-Estuary & $118^{\circ} 34^{\prime} 40.77^{\prime \prime} \mathrm{E}$ & $38^{\circ} 06^{\prime} 17.74^{\prime \prime} \mathrm{N}$ & 82 & 42 & 40 & 15 & 7 & 6 \\
\hline 2 & Artificial coast & $119^{\circ} 03^{\prime} 41.04^{\prime \prime} \mathrm{E}$ & $37^{\circ} 55^{\prime} 55.87^{\prime \prime} \mathrm{N}$ & 94 & 49 & 51 & 18 & 10 & 6 \\
\hline 3 & Estuary coast & $119^{\circ} 17^{\prime} 06.34^{\prime \prime} \mathrm{E}$ & $37^{\circ} 47^{\prime} 14.14^{\prime \prime} \mathrm{N}$ & 98 & 58 & 83 & 78 & 10 & 5 \\
\hline 4 & New-coast & $119^{\circ} 06^{\prime} 37.58^{\prime \prime} \mathrm{E}$ & $37^{\circ} 38^{\prime} 45.50^{\prime \prime} \mathrm{N}$ & 84 & 42 & 48 & 35 & 8 & 3 \\
\hline 5 & Stable-coast & $118^{\circ} 57^{\prime} 27.52^{\prime \prime} \mathrm{E}$ & $37^{\circ} 34^{\prime} 25.84^{\prime \prime} \mathrm{N}$ & 86 & 43 & 50 & 36 & 8 & 5 \\
\hline 6 & Branch -sea & $118^{\circ} 56^{\prime} 40.84^{\prime \prime} \mathrm{E}$ & $37^{\circ} 21^{\prime} 02.88^{\prime \prime} \mathrm{N}$ & 80 & 39 & 37 & 15 & 8 & 6 \\
\hline
\end{tabular}

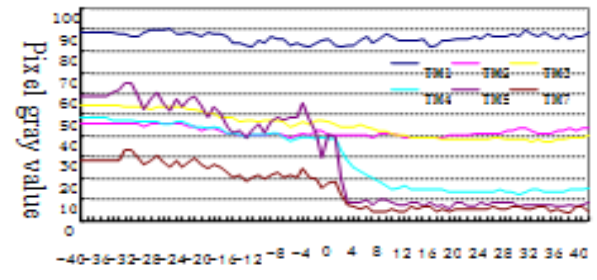

The distance of sample

Figure 1. Gray value features of NO.1 sample point

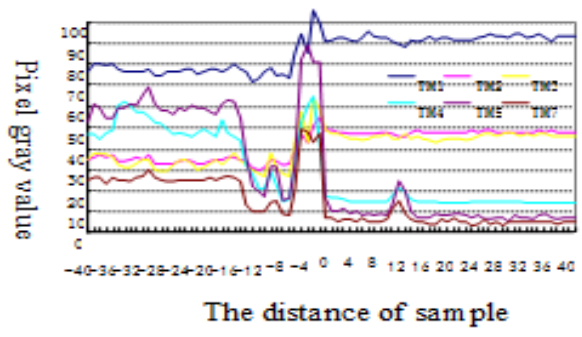

Figure 2. Gray value features of NO.2 sample point

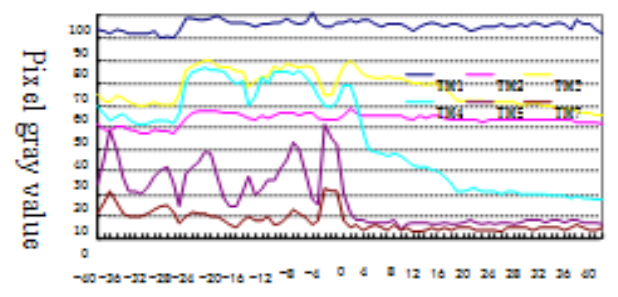

The distance of sample

Figure 3. Gray value features of NO.3 sample point

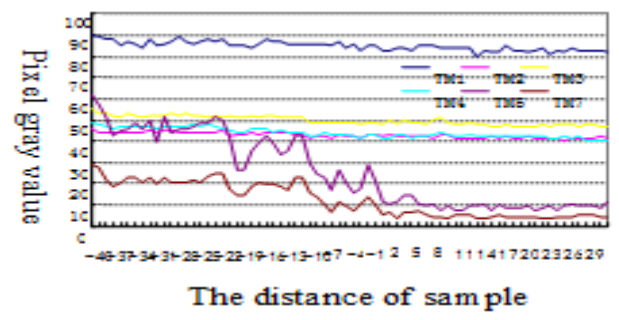

Figure 4. Gray value features of NO.4 sample point

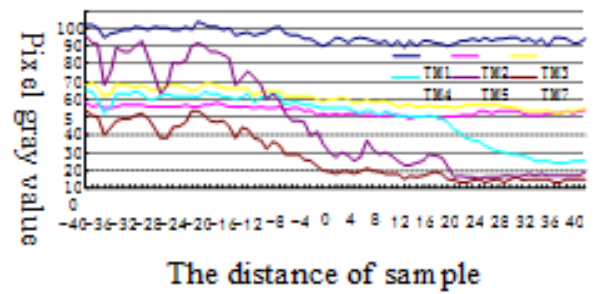

Figure 5. Gray value features of NO.5 sample point

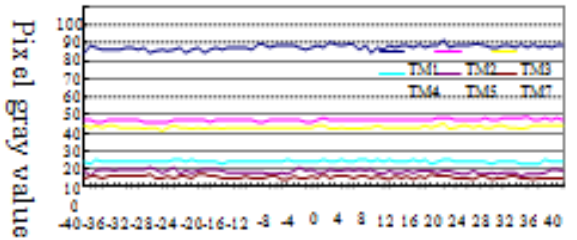

The distance of sample

Figure 6. Gray value features of NO.6 sample point

Table 2 The gray-scale statistical analysis of 40 pixels in water near the six features points

\begin{tabular}{|c|c|c|c|c|c|c|}
\hline $\begin{array}{c}\text { Sample } \\
\text { numbering }\end{array}$ & TM1 & TM2 & TM3 & TM4 & TM5 & TM7 \\
\hline 1 & 86.32 & 40.79 & 39.26 & 14.68 & 8.26 & 5.00 \\
\hline 2 & 92.95 & 47.89 & 45.71 & 15.03 & 8.53 & 5.53 \\
\hline 3 & 95.45 & 53.37 & 63.47 & 25.00 & 6.92 & 4.58 \\
\hline 4 & 82.82 & 41.34 & 47.84 & 41.26 & 9.58 & 5.16 \\
\hline 5 & 82.89 & 41.37 & 45.87 & 28.76 & 8.13 & 5.82 \\
\hline 6 & 77.76 & 37.32 & 33.29 & 14.11 & 8.29 & 5.32 \\
\hline Mean & 86.36 & 43.68 & 45.91 & 23.14 & 8.29 & 5.23 \\
\hline $\begin{array}{c}\text { Standard } \\
\text { deviation }\end{array}$ & 6.70 & 5.85 & 10.15 & 10.79 & 0.85 & 0.43 \\
\hline
\end{tabular}

After analyzing samples of six typical waters near 40 pixel (Table 2) can be seen that the gray value variation amplitude of TM5 and TM6 is small. Therefore, it is suitable for land and sea border line analysis. 


\subsection{The process of automatic extraction coastline}

\section{1) Geometric precision correction}

In order to ensure the accuracy of the extraction and field tested shoreline, all images need to be geometric precision correction[11]. According to the technical procedures required, data are unified to $117^{\circ}$ that the central meridian of $6^{\circ}$ with Gauss Kruger projection on topographic maps. On the 1:50,000 topographic maps selected 126 evenly distributed ground control points for image correction with using WGS 84 coordinate system and the 1985 National Height Datum. It ensures the correction accuracy within 0.5 pixels.

\section{2)Radiometric Correction}

Radiometric calibration is the process of eliminating or correcting a variety of noise that additional radiation energy of remote sensing images in the imaging process[12]. Sensor receives electromagnetic radiation energy and the targets itself are inconsistent since the complexity of remote sensing image imaging process[13]. Sensor output energy also contains a variety of distortion due to the sun's position and angle conditions, atmospheric conditions, topography and the performance of the sensor itself caused[14]. These distortions are not the ground target's radiation. It impacts that the image understand and use. Therefore, it must be corrected or eliminated. In this paper, Dark Target is used to radiation correction [15].

\section{3) Wavelet Transform}

(1) The original image makes three-scale wavelet transform[16]. The filter $h(n)$ and $g(n)$ of Values were

$\mathrm{h}(\mathrm{n})=[0.0625,0.25,0.375,0.25,0.0625]$

$\mathrm{g}(\mathrm{n})=[-0.01643,-0.10872, \ldots 0.59261,0$, 0592 61, 0108 72, 0016 43]

$\mathrm{h}(\mathrm{n})$ is a low pass filter and $\mathrm{g}(\mathrm{n})$ is a high-pass filter which is used to detect the edge of the step type[17].

(2) Calculating transform modulus and angle of each layer with using the results of wavelet transform. We detect the local maxima map though using the modulus and the argument map. The algorithm is described as follows[18]:

a) Calculating three- scales mode binary image.

b) If $|\operatorname{Mod}(j, x, y)|<\varepsilon$, then $\operatorname{Mod}(j, x, y)=0$.

c) When calculating the argument, the argument will be divided into four directions (the horizontal direction, $45^{\circ}$ direction, the vertical direction and the $135^{\circ}$ direction).

d) We detected local maxima along the radial direction. The first layer has more wavelet edge points. Next, with the increase of the number of layers, the modulus value of the noise is less than the threshold and it is set to 0 . It does not appear in the image local maxima point. Thus, it has fewer edge points as the scale increases.

(3) Through the use of public space consistency condition, we selected these three layers edge point conversion. Since the noise points in the second and three layers have been inhibited, we can get a real step - edge points. By such processing, the impact of noise on the image edge detection is eliminated. The edge points obtained basically belong to the real step edge.

\section{4) Automatic seed growth}

(1) Select the initial seed point

We divide the image into $\mathrm{N}$ equal portions $(3 \times 3$ or $5 \times 5)$ and find the area of smallest variance and mean. Then we again divide the image into $\mathrm{N}$ equal portions and find the area of smallest variance and mean until it cannot be divided up[19]. We select the central pixel of each region as the initial sample.

\section{(2) Determination threshold}

It is necessary to determine a threshold value $\mathrm{T}$ when seeds grow. When a seed point points of the gray value in the neighborhood is less than the threshold value, we believe that the points in the neighborhood and the seed point are the same point within an area[20].

The threshold value depends on the detected image[21]. If the currently detected image of sea is relatively simple, $\mathrm{T}$ should be smaller which can reduce the probability of false. If the currently detected image of sea is relatively complex, $\mathrm{T}$ should be larger which can increase the probability of detection. The following formula can calculate the threshold T[22]

$$
\left\{\begin{aligned}
\mu & =\frac{1}{\mathrm{~N}} \sum_{i=0}^{\mathrm{N}-1} f\left(x_{\mathrm{i}}\right) \\
\sigma & =\sqrt{\frac{1}{N} \sum_{i=0}^{N-1}\left(f\left(x_{i}\right)-\mu\right)^{2}} \\
T & =\mu+a \sigma
\end{aligned}\right.
$$

Where $\mathrm{N}$ is all points of the river area which has been detected, $f(x i)$ is $i$-th pixel gray value. $a$ is an adjustable coefficient and it can extract automatically though a computer.

In order to increase the speed and reduce the computing time, we can make change of the following formula[23].

$$
\sigma^{2}=E\left\{\left(f\left(x_{i}\right)-\mu\right)^{2}\right\}=E\left\{f\left(x_{i}\right)^{2}\right\}-\mu^{2}
$$

Only a few multiplications and a root operation can be updated thresholds $\mathrm{T}$.

\section{(3) The algorithms of growth}

Properties of all the pixels initialized the entire image to "unknown" state. This algorithm defines all pixel attribute to three states[24] (river area, sea area and land). 
To reduce the dependence final results of coastline detection with the initial seed point. The algorithm computes local mean and variance of all the pixels in the initial seed regions. We can get the initial threshold and update continually in subsequent calculations.

(4) Extraction and refinement of coastline

We get pixel gray value of standard samples in each band, analyze gray scale-range of each band and determine the variance. Image binarization method is used though setting variance of a threshold value [25]. We refine image through the method of the central axis transformation and get the whole coastline.

Figure 7 shows the extraction process of the coastline.

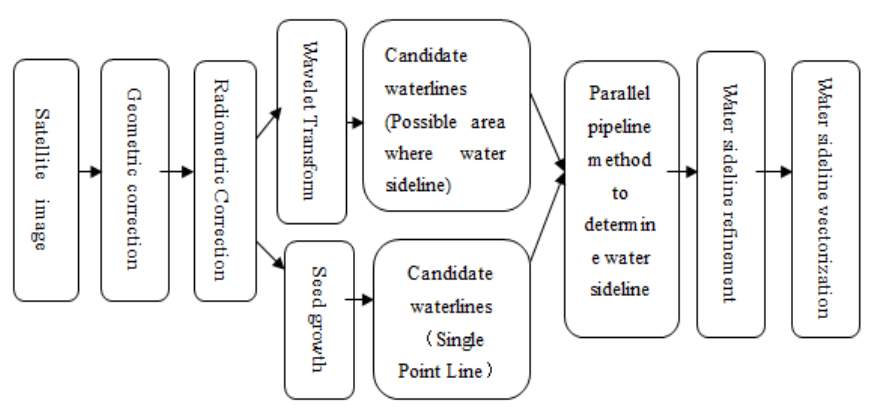

Figure 7. Flow chart of extracting coastline

\section{EXPERIMENTAL RESULTS}

\subsection{Extraction of coastline}

We extracted the coastline by morphological algorithm of wavelet transform (Figure 8). Figure 9 shows the superposition of its results and remote sensing images.

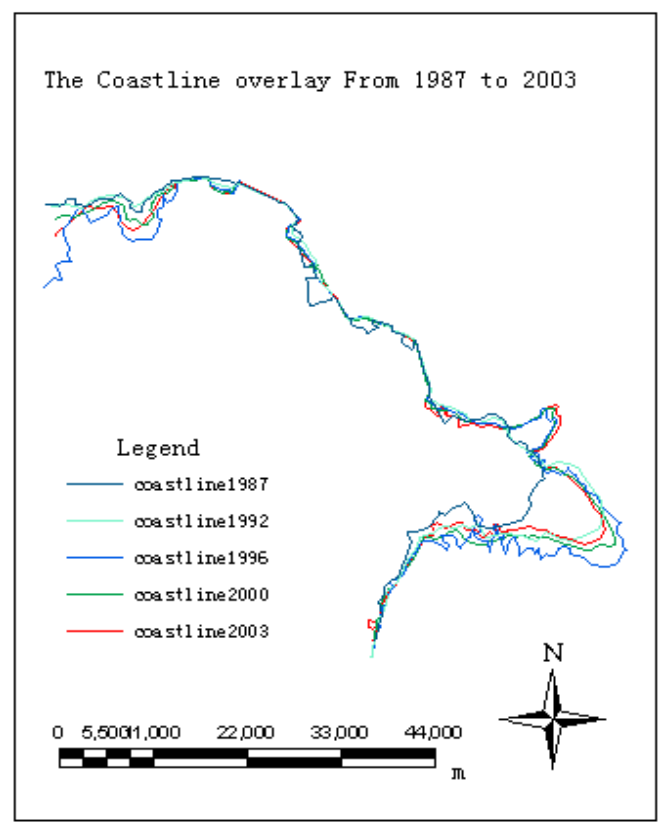

Figure 8. Coastline extraction results

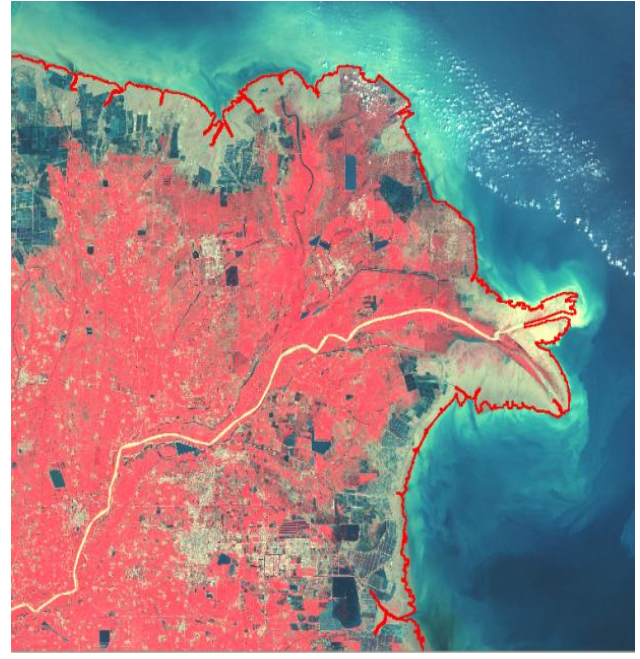

Figure 9. Coastline extraction results and remote sensing image superimposed display

The image (Figure 8) of overlay coastline from 1987 to 2003 shows the overall trend in the evolution of the Yellow River Delta. The coastline of the Yellow River estuary presents silting trend in the river-flowing period. The shoreline is erosion in the non-flowing period due to the role of ocean dynamics [26]. The change in the coastline occurred mainly in the estuary and Diao mouth area, while other coast is relatively stable.

The results show that the shoreline moved quickly towards the sea in the river-flowing period, and retreated in the non-flowing period because of the wind, wave and tidal current. The changes in the coastline mainly occurred in the estuary and Diao mouth area and other coast is relatively stable. The coastline was mainly silt from 1987 to 1992 and the coastline moved towards the sea in the estuary area and Diao mouth area, but the shoreline of Guangnan reservoir suffered slight erosion in the southern. The spit of estuarine expanded rapidly due to the large amount of sediment deposition and extends continually along the southeast, but the top was not fully siltation and it forms a large vacancy. The coastline undergone major changes, the estuary produced large amounts of silt, the spit projected quickly into the sea along the southeast direction and the top of spit changed gradually from blunt to taper from 1992 to 1996. The northern of spit had been accreted rapidly into small sand spit because the Yellow River diverse into the sea from North Branch in July, 1996. The west side of Diao Mouth River retreat severe erosion because Delta winds northeasterly throughout the year. The spit of south and small spit of north had been eroded slowly and the top of spit tended to smooth because the amount of runoff and sediment reduced dramatically in Yellow River from 1996 to 1998. Part of the coastline on south of Guangnan reservoir was slight erosion. The deposition and erosion were alternated frequently, the shoreline advanced and retreated and changed little from 1998 to 2000 . The small spit in 
the north of the estuary extend continually to the sea. The shoreline Yellow River had taken place erosion across the board because runoff and sediment reduced in Yellow River from 2000 to 2003. However, the magnitude of shoreline suffered minor erosion.

\subsection{Accuracy Evaluation}

In order to evaluate accuracy of automatic extraction coastline based on wavelet transform method of morphology shoreline extraction, we compared the data of measured coastline in 1984 to extraction coastline of TM image in May 1984. The specific method is what superimposed the measured data and extracts the results on the TM images (Figure10). We select uniformly 30 regional sections of coastline in the measured data (Figure11) and selected randomly a measured point in each region and calculated minimum distance of the point to extraction coastline (Table 3 ).

Table 3 The Minimum distance of 30 measured verification

\begin{tabular}{|c|c|c|c|c|c|c|c|}
\hline \multirow{2}{*}{$\begin{array}{c}\text { Measured } \\
1\end{array}$} & \multicolumn{2}{|c|}{ Coordinates } & \multirow{2}{*}{$\begin{array}{c}\text { extract } \\
1\end{array}$} & \multicolumn{2}{|c|}{ Coordinates } & $\frac{\text { Distance }}{\mathrm{m}}$ & $\begin{array}{l}\text { Error } \\
\text { pixels } \\
\end{array}$ \\
\hline & 466399 & 4225275 & & 466144 & 4225162 & -279 & 9 \\
\hline 2 & 475262 & 4223704 & 2 & 475383 & 4223696 & -121 & 4 \\
\hline 3 & 484648 & 4221215 & 3 & 484735 & 4221254 & -95 & 3 \\
\hline 4 & 488446 & 4222129 & 4 & 488420 & 4222178 & -55 & 2 \\
\hline 5 & 495124 & 4221640 & 5 & 495114 & 4221688 & -49 & 2 \\
\hline 6 & 504313 & 4218722 & 6 & 504250 & 4218722 & 63 & 2 \\
\hline 7 & 512450 & 4226613 & 7 & 512416 & 4226598 & 37 & 1 \\
\hline 8 & 522834 & 4225253 & 8 & 522743 & 4225219 & 98 & 3 \\
\hline 9 & 533122 & 4223164 & 9 & 533175 & 4223294 & -141 & 5 \\
\hline 10 & 536677 & 4221136 & 10 & 536711 & 4221213 & -84 & 3 \\
\hline 11 & 540965 & 4215755 & 11 & 540955 & 4215895 & -140 & 5 \\
\hline 12 & 541862 & 4209858 & 12 & 541862 & 4209860 & 2 & 0 \\
\hline 13 & 545874 & 4203370 & 13 & 546000 & 4203525 & -199 & 7 \\
\hline 14 & 549598 & 4200804 & 14 & 549492 & 4200708 & 143 & 5 \\
\hline 15 & 552185 & 4196625 & 15 & 552166 & 4196656 & -37 & 1 \\
\hline 16 & 553514 & 4192383 & 16 & 553456 & 4192537 & -165 & 5 \\
\hline 17 & 555007 & 4188536 & 17 & 555198 & 4188440 & 214 & 7 \\
\hline 18 & 563798 & 4186431 & 18 & 563682 & 4186431 & 116 & 4 \\
\hline 19 & 565486 & 4182813 & 19 & 565380 & 4183103 & 308 & $10 * * *$ \\
\hline 20 & 561540 & 4172115 & 20 & 561564 & 4172192 & 81 & 3 \\
\hline 21 & 555405 & 4172974 & 21 & 555347 & 4173041 & 89 & 3 \\
\hline 22 & 550476 & 4171845 & 22 & 550442 & 4171903 & -67 & 2 \\
\hline 23 & 549646 & 4171391 & 23 & 549670 & 4171382 & -26 & 1 \\
\hline 24 & 546164 & 4168758 & 24 & 546178 & 4168642 & 117 & 4 \\
\hline 25 & 543587 & 4164648 & 25 & 543587 & 4164630 & -18 & 1 \\
\hline 26 & 539922 & 4155137 & 26 & 540076 & 4155195 & 165 & 5 \\
\hline 27 & 540183 & 4149908 & 27 & 540269 & 4149850 & 104 & 3 \\
\hline 28 & 540530 & 4145490 & 28 & 540694 & 4145345 & 219 & 7 \\
\hline 29 & 541451 & 4142852 & 29 & 541355 & 4142895 & -106 & 4 \\
\hline 30 & 541639 & 4136654 & 30 & 541613 & 4136683 & 39 & 1 \\
\hline
\end{tabular}

*** The average error of image is 4 pixels 


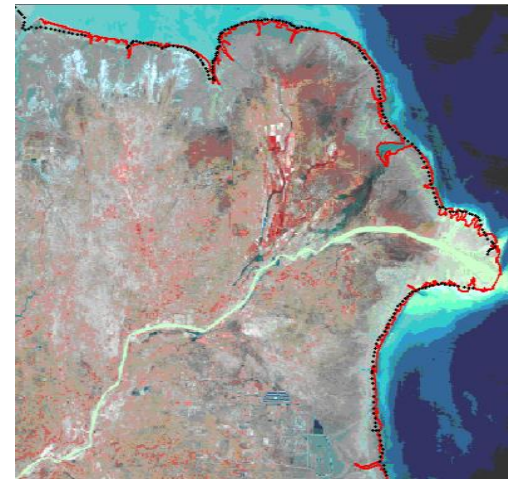

Figure 10. Superimposed TM images of measured results and extract results*

*. The measured coastline in 1984

- The extracted coastline of TM images in 1984

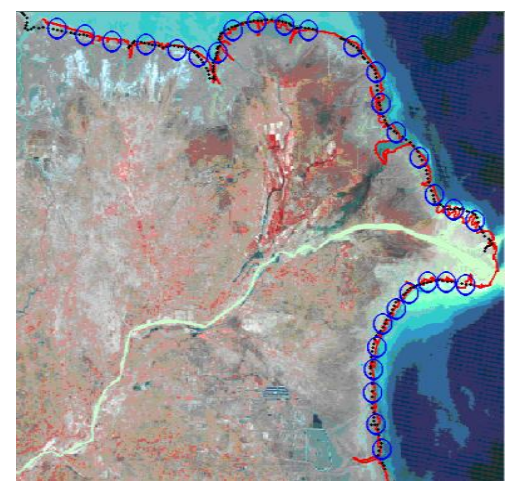

Figure 11 . The area of verification point $* *$ **. The measured coastline in 1984

- The extracted coastline of TM images in 1984

The area of 30 verification points

Table 3 shows that the maximum error of image is 10 pixels and the average error of image is 4 pixels. The spatial distribution of the verification and the changes of error show that the algorithm has a big error in the larger area of the beach area of the Muddy. It's mainly due to tidal change which causes the change of instantaneous water sideline and results in the inconsistent of the result of water sideline with the values measured. The results of artificial shoreline are more accurate and smaller error. However, the algorithm does not consider the impact of ocean tides due to the lack of tides data.

\section{CONCLUSION}

This paper proposes coastline automatic extraction algorithm mathematical morphology of based on wavelet transform according to the spectral characteristics of the coastline and its characteristics. The algorithm does not need to specify basically any parameters and implements a fully automated extraction of coastline. Experimental results show that the extracted accuracy of the algorithm. It can get complete coastline though bypassing those gray values abnormal. The algorithm has a certain capability of anti-noise.

\section{REFERENCES}

[1] Kevin White \& Hesham M. El Asmar. 1999. Monitoring changing position of coastlines using Thematic Mapper imagery, an example from the Nile Delta. Geomorphology 29: 93 105.

[2] Xu Xuegong.1986. Deriving muddy coast beach low tide line by the use of remote sensing images. Journal of Shandong Normal University (Natural Science), (4): 34 43.

[3] Huang Haijun \&Li Chengzhi. 1994. Application of Landsat Image to the Shoreline Changes of the HuangHe River Delta. Marine Geology \& Quaternary Geology, 14(2): 29 37.

[4] Huang Haijun \& Fan hui. 2004. Monitoring Changes of Nearshore Zones in the Huanghe (Yellow River) Delta Since 1976. Oceanologia ET Limnologia, 35(4): 306 314.

[5] Ji Zuwen \& Hu Chunhong \& Zeng Qinghua. 1994. Analysis of Evolution of the Yellow River Estuary by landsat image. Journal of Sediment Research, (3):12 22.

[6] He Qingcheng \&Duan Yonghou. 1999. Integrated Coastal Zone Management of Yellow River Delta-Looking to the 21st century from the perspective of Earth Sciences. Beijing: The Press of Ocean.

[7] Fan Yaomu \& Guo Yongsheng. 1992. The Atlas Dynamic analysis of remote sensing along the Yellow River Delta. Beijing: The Press of Ocean.

[8] Zhang Shihua.2003.Coastline Change and Coast Protection in the Yellow River Delta. Marine Science, 27(10): 38 41.

[9] Zeng Qinghua. 1997. Evolution and Remediation of the Yellow River Estuary. Zhengzhou: The Conservancy Press of Yellow River.

[10] Chang Jun\& Liu Gaohuan \& Liu Qingsheng. 2004. Analysis on spatio-temporal feature of coastline change in the Yellow River Estuary and its relation with runoff and sand-transportation. Geography Research, 23(3):339 346.

[11] Buli Cui \& Xueli Chang. 2006. The Impact of Hydrological Characteristics of the Yellow River Coastline Changes in the Yellow River Delta. Journal of Natural Resources, 21(6): 957-964.

[12] Yang Yuzhen \& Liu Gaohuan \& Liu Qingsheng. 2004. Ecology and Natural Resources in Yellow River Delta Digital Integration. Henan: Conservancy Press of Yellow River.

[13] Frazier P S \& K J Page. 2000. Water body detection and delineation with Landsat TM data. Photogrammetric Engineering and Remote Sensing, 66 (2): 1461 1467.

[14] Kevin W\& E I Asmar H M. 1999.Monitoring changing position of coastlines using thematic mapper imagery, an example from the Nile Delta. Geomorphology, 29: 93 105.

[15] Manavalan P \& Sathyanath P \& Rajegowda GL. 1993. Digital image analysis techniques to estimate water spread for capacity evaluations of reservoirs. Photogrammetric Engineering and Remote Sensing, 59 (9): 1389 1395.

[16] Joo Hyung Ryu \& Joong SunWon \& Kyung Duck Min. 2002.Water Extraction from Landsat TM Data in a Tidal Flat: A Case Study in Gomso Bay, Korea. Remote Sensing of Environment, 83 (3): 442 - 456. 
[17] Le Moigne J \& Tilton J C. 1995.Refining Image Segmentation by Integration of Edge and Region Data. IEEE Trans. Geo sci. Remote Sens. 33: 605-615.

[18] Richard L \& Miller, etc. 2004 .Using MODIS Terra 250m imagery to map concentrations of total suspended matter in coastal waters. Remote sensing of Enviroment, 93: 259 266.

[19] Lira J \& Morales A \& Zamora F. 1997. Study of sediment distribution in the area of the Panuco River plume by means of remote sensing. International Journal of Remote sensing, 18 (1):171 182.

[20] Forget \& Philippe \& Ouillon, etc. 1998.Surface suspended matter off the Rhone river mouth from visible satellite imagery. Oceanologica Acta, 21 (6):739 749.

[21] Hu Chuanmin \& Carder Kendall L \& Muller Karger \& Frank E. 2000.Atomospheric correction of SeaWiFS imagery over turbid coastal Waters. Remote sensing of Environment, 74(2):195 206.
[22] Ruhl C A. 2001. Combined use of remote sensing and continuous monitoring to analyse the variability of suspended-sediment concentration in San francisco bay california. Coastal and Shelf Science, 53:801 812.

[23] Bowers D G \& Gaffney S \& White M,et al. 1998. Turbidity in the southern Irish Sea. Continental Shelf Research, 18(5):487 500.

[24] David Doxaran. 2002 .Spectral signature of highly turbid waters Application with SPOT data to quantify suspended particulate matter concentrations. Remote Sensing of Environment, 81:149 161.

[25] Froidefond J M \& Gardel L \& Guiral D \& et al. 2002 .Spectral remote sensing reflectances of coastal waters in French Guiana under the Amazon influence. Remote sensing of Enviroment, 80:225 232.

[26] Palmer P L \& Petrou M. 1997.Locating Boundaries of Textured Regions. IEEE Trans. Geo sci. Remote Sens. 35(5): 1367-1371. 